\title{
EXPERIENCES OF PHYSIOTHERAPY STUDENTS IN A CliniCAL SETTING FOR ELDERLY ADULTS
}

\begin{abstract}
The purpose of this study was to assess and describe qualitatively the learning experiences of physiotherapy students within the context of a clinical education setting where students learnt to provide care for elderly adults. Data collected over two years from students' diaries kept during the block, and individual or group interviews, were analyzed. Two major themes were vital to the students, namely coping with disability and

AMOSUN SL (BSc Physiotherapy, PhD Physiologyl'

1 Department of Physiotherapy,

University of the Western Cape reduced functional ability in elderly adults, as well as dealing with death and dying. The study concluded that there is a need for clinical integration of the concepts of chronic disability, death and bereavement in physiotherapy education.
\end{abstract}

\section{KEY WORDS: PHYSIOTHERAPY, EDUCATION, STUDENTS, OLDER PERSONS, EXPERIENCES}

\section{INTRODUCTION}

The increasing number of elderly adults in South Africa requires that physiotherapy students gain necessary skills in information gathering, assessment, and treatment applied to geriatric patients. This calls for creative inclusion of elderly adults in learning experiences for students in physiotherapy education programs. In the United States of America, the primary purpose of geriatric training at medical schools was to improve the care of the elderly by increasing their knowledge base and fostering interest in older patients of practitioners in every specialty (Barry 1994). A secondary goal was to interest some students in selecting geriatrics as a career.

It is common practice for physiotherapy educators and clinical supervisors to develop core-learning objectives for physiotherapy students to work towards when they embark on clinical placements focusing on the needs of elderly adults (Simpson et al, 1993). It is assumed that several features of these objectives distinguish them from those set for other areas of physiotherapy practice. The loss of function is usually gradual in elderly adults. Inevitably, there are those who would require long-term care as they become too frail to manage on their own (Harpur et al., 1994). Often these individuals also have multiple problems associated with advanced age, and meeting their needs often presents challenges to students and qualified practitioners. Attempts at meeting these needs seem to influence physiotherapy educators in the development of core-learning objectives for physiotherapy students during geriatric clinical placements.

Unfortunately, none of the learning objectives seem to prepare students to cope with the experience of relating to individuals who may suffer from chronic disability and limited function (Harpur et al., 1994). In addition, the objectives do not seem to prepare students to cope with patients who may encounter death due to old age or other causes.

Physiotherapy students at University of the Western Cape are often sent to a government-subsidized residence for elderly adults in the southern suburb of Cape Town. The residence offers long stay continuing-care accommodation for three groups of older persons, namely a frail care group, a nursing assistance group, and a fully independent group. The residence provides full time medical and nursing care, in addition to physiotherapy and occupational therapy services.

In the recent past, the students expressed feelings of shock and revulsion to the author on their experiences during on this particular geriatric clinical education block. In some cases, students were reluctant to continue with the block. For some, it was the first time of interaction with "an old helpless person who died in spite of all physiotherapy care". The encounter with the death of some clients seemed to have raised questions about chronic disability, death and dying, and the fear of death among the students. A strategy was therefore put in place to reduce the perceived concerns of the students. Once a wẹek during the geriatric block, the author had individual or group discussions during which students were encouraged to express their feelings and thoughts openly.

Two earlier studies focusing on the physiotherapy education program in the University of the Western Cape identified burnout among the students (Amosun and Dantile, 1996), and possible contributing factors included in their experiences during clinical education (Simuzingili and Amosun, 1998). The concerns raised from the two earlier studies as well as the concerns expressed by students during past geriatric clinical blocks prompted the present study. This study was therefore undertaken to assess

\section{CORRESPONDENCE TO:}

Prof SL Amosun

Department of Physiotherapy University of the Western Cape Private Bag X17, Bellville 7535 E-mail: samosun@chs.uwc.ac.za Tel: (021) 959-2542 Fax: (021) 959-2804 
and describe the learning experiences of physiotherapy students within the context of one clinical education setting where students learnt to provide care for elderly adults. The author proposed that physiotherapy students at the University of the Western Cape were adequately prepared to face whatever challenges they encountered in a geriatric clinical education setting.

\section{METHOD}

\section{Research Setting}

At the University of the Western Cape, physiotherapy students enter an eight semester undergraduate program. Till the end of 1999 , the first four and a half semesters were spent at the University with limited exposure to the clinical environment. In the remaining semesters, students were expected to rotate through eight clinical education blocks spending four to five weeks in each block. The blocks included a geriatric block, a community block, a general block (respiratory, orthopaedics, neurology), and a rehabilitation block (includes spinal cord injuries). The remaining blocks were paediatrics, outpatients, intensive care and an elective block. Students normally went through the geriatric block during their third year of training, and were often in groups of four students. Students were required to work under supervision for 40 hours a week while on the block.

\section{Procedure}

All students in the selected clinical facility were required to keep diaries about their experiences of daily encounters with patients during the clinical education block. At the end of the block, the students were also required to diarise a summary of their experiences. In addition, individual or group interviews were conducted with the students towards the end of each block at the clinical site, as a means of block evaluation. At the beginning of the 1998 and 1999 academic sessions, all 3rd year students were informed about the intention of the author to obtain an overview of the experiences the students encountered while on the particular clinical block. All the diaries of students who agreed to take part in this study were collected at the end of each block.

At the end of the 1999 academic session, the narratives in the diaries and end of block interviews were analyzed retrospectively to identify recurring themes (Fagerberg, Ekman 1998). In addition, the author utilized extracts from the students' diaries, which were considered to be representative of the views expressed by majority of the students, to describe the experiences of the students.

\section{Resulf}

Between 1998 and 1999, thirty-two students passed through the selected clinical facility, and 20 students $(62.5 \%)$ submitted their diaries to be analyzed. During end of block interviews, the participating students (male and female) indicated that the block was not the first time they had opportunity to interact with older people.

Going through the diaries of the students and listening to issues raised during individual or group interviews, two major themes appeared vital to the students. The first concern related to the ability of the students to cope with chronic disability and reduced functional ability in elderly adults. There was a general perception among the students that, in spite of the clinical diagnoses, many of their patients were helpless and suffering because of neglect, and these perceptions seemed to have impact on the students. One student summarized her experience:

"My experience in this block threw me off balance to begin with. My first patient was incontinent and it seemed as if no one really cared. I understand that the nurses have many people to attend to and that no one person can get special treatment. I was aware of the degradation that the patient must have felt. I find it a tragedy that the patient was subjected to humiliating conditions on a daily basis. I felt extreme distress and wondered whether I could deal with this."

Another student reported:

"My first impression was one of neglect and suffering, and though that has not changed, I have taken it upon myself to at least improve the quality of life of those few people that I work with."

Unfortunately, the students expressed different degrees of frustration in their attempt at improving the status of their clients. The students set out and implement treatment objectives based on the clinical diagnoses of the clients, but expressed their own inadequacies as to what to do to alleviate the 'helplessness' of their clients. One student summarized the frustration thus:

"I am getting frustrated by the lack of progress with my patients. I would like to overlook the lack of progress and find some other way to assess whether or not what I am doing is having a positive effect or not."

The second major challenge to the students was dealing with death and dying. Some of them encountered patients who expressed the desire to die, and refused treatment. The students felt helpless in handling such cases. Students whose patients died reported that they felt "bad and hopeless". Some students acknowledged that their fear was related to their ignorance of what to expect and how to know when a patient is dying. Only four students had opportunity to see a dying patient, and the experiences made an impact on them. One student vividly described her experience:

"I heard a scream like a baby crying. One of the night sisters, the doctor and assistant nurses appeared. I never saw a person dying in my life. She was fighting like anything, as if she was going to survive. Yet it was the end for her I was so shocked to see that she was dead whereas her eyes were still opened. To be calm is very important in such a situation, to think, to know what to do. As a result, I could not sleep well, and the following day I woke up with a terrible headache. I have to be calm in order to cope with real life."

While many students addressed negative aspects of their experiences during the block, some students also commented 
on feelings of excitement and discovery. An experience of one of the students is described below:

"I was assigned a respiratory patient with COAD (chronic obstructive airway disease). He was nebulized every morning before breakfast. At first he needed to be nebulized, but as he improved I stopped. He demanded it and though my culture expected me to obey older people, I refused. I explained to him the risks of nebulizing. It was hard for me to draw the line with the patient pleading, but it was a good learning experience for me to make a decision and stick by it. I have gained confidence in decision making through this experience."

The following comment sums up a sentiment expressed by many students:

"I think that this block has been an incredible learning experience, and the most important lesson that I learnt is to treat patients as people, not conditions. I have been able to overcome many difficulties and have learnt a great deal, probably the most important aspect of being a physiotherapist, which is the ability to treat people, not patients."

\section{DISCUSSION}

Physiotherapy educators have an obligation to train practitioners who will meet the needs of the society that they will serve. In their attempt to provide service to older persons, physiotherapy students in this study experienced certain challenges. It is therefore important that the needs of the students in meeting these challenges should be identified, and appropriate solutions put in place to avoid increasing their levels of stress (Amosun and Dantile, 1996; Simuzingili and Amosun, 1998). Physiotherapy educators can only enhance learning by being sensitive to these needs while developing clinical objectives (Hayes et al., 1999). Ignoring these needs may lead to unsafe or ineffective practice. Concerns about the needs may also influence students in their selection of preferred clinical placements (Fagerberg et al., 1997).

The issue of chronic disability is of prime importance in physiotherapy practice, especially its impact in elderly adults (Clarke 2000). Physiotherapists and physiotherapy students are often faced with ethical and psychosocial dilemmas. Clarke (1998) explained the phenomenon of suffering in chronic disability when there is a threat to the "personhood" of the client. Unfortunately, physiotherapists tend to apply treatment interventions to alleviate the symptoms of chronic disability when in fact the client is really experiencing suffering. In such instances, the treatments are ineffective and the physiotherapist may incorrectly lose confidence in the efficacy of a particular treatment technique. Clarke (1998) reported the need for implementing the concept of suffering into assessment and treatment regimes. In the current study, while the students had some skills in assessing the functional limitations in chronic disability, the students were unable to appreciate the threat to the "personhood" of their clients. It may be helpful to assist students to have a better understanding about the role that the phenomenon of suffering plays in chronic disability. This may better equip the students to assist their clients to attain their optimal rehabilitation potential.

Physiotherapy students receive very limited systematic training in caring for dying people. The majority of physiotherapy education training focuses on technical skills. A similar situation was reported in the medical education program in Oregon Health Science University (Bascom et al., 1999). Fortytwo percent of students who graduated between 1996 and 1998 never had the opportunity to care for dying patients. Preparing students to face the loss of patients through suffering and death is not an easy task. The experiences reported in this study represented a poignant but emotionally draining aspect of students' clinical education experiences, which make adjusting to deathrelated encounters a particular challenge for students. A clear implication is the need for effective guidance and support to be provided by the system and by individual members of the teaching and clinical staff in improving students' coping mechanism.

Physiotherapy students face their own fear of death whenever they come to the bedside of a dying patient. This fear must be confronted and reconciled before they can help others meet death with dignity. Examining one's attitude towards death is a difficult task that needs to begin in the student years when attitudes towards working with the dying are formed. Barnard et al., (1999) reported that basic end-of-life care competencies are in five domains namely: (i) psychological, sociologic, cultural and spiritual issues; (ii) interviewing and communication skills; (iii) management of common symptoms; (iv) ethical issues; and (v) self-knowledge and selfreflection. Most of these competencies are already included in physiotherapy education curricula, and physiotherapy educators should identify effective ways of promoting necessary awareness among students. A time to begin may be during human dissection in anatomy (Hancock et al., 1998).

At the onset of this study, the author proposed that physiotherapy students at the University of the Western Cape were adequately prepared to cope with all challenges encountered during the geriatric block. The findings suggest that the students were unsure in coping with chronic disability, dying and death. However, the generalization of the results to other physiotherapy students and programs should be done with caution since data was gathered from physiotherapy students from only one university.

\section{CONCLUSION}

It is not possible to equip physiotherapy students with al] the practical skills that they are likely to need. Professional education curricula should extend beyond the learning of discipline-specific skills to encompass broader learning goals which will enable the students to function better within clinical environments. If physiotherapy educators deal adequately with the moral and psychosocial issues presented in the clinical education settings, they assist students to formulate appropriate attitudes and behaviours towards patients. There is a critical need of adequate and contemporary clinical integration of chronic disability, death and bereavement concepts in physiotherapy education. 


\section{REFERENCES}

Amosun SL, Dantile ND 1996 Evaluating physiotherapy education at the University of the Western Cape - Are we graduating physiotherapists with the burnout syndrome? South African Journal of Physiotherapy 52:69-72

Barnard D; Quill T; Hafferty FW; Arnold R Plumb J; Bulger R; Field M 1999 Preparing the ground: contributions of the preclinical years to medical education for care near the end of life. Working Group on the Pre-clinical Years of the National Consensus Conference on Medical Education for Care Near the End of Life. Academic Medicine 74:499-505

Barry PP 1994 Geriatric clinical training in medical schools. American Journal of Medicine 97:4A, 8S-9S

Bascom P, Vetto JT, Osborne M 1999 Clinical experiences of medical students in Oregon with dying patients. Journal of Cancer Education 14:137-139
Clarke BM 1998 Pain, suffering and physiotherapy. Physiotherapy Canada 50:112-122

Clarke BM 2000 The impact of suffering in physiotherapy practice: Cost containment issues. Physiotherapy Canada 52:25-32

Fagerberg I, Ekman SL 1998 Swedish nursing students' transition into nursing during education. West J Nursing Research, 20:5, 602-20

Fagerberg I, Ekman SL, Ericsson K 1997 Two studies of the new nursing education in Sweden: $\mathrm{I}$. The place of gerontology and geriatrics. Nurse Education Today, 17:2, 150-7

Hancock D, Williams M, Taylor A 1998 Psychological impact of cadavers and prosections on physiotherapy and occupational therapy students. Australian Journal of Physiotherapy 44:247-255
Harpur WE, Coalter A, Lennon SM, Breadon E 1994 An appraisal of the effectiveness of physiotherapy intervention in elderly continuing-care patients: single case series. Physiotherapy 80:682-686

Hayes KW, Huber G, Rogers J, Sanders B 1999 Behaviours that cause clinical instructors to question the clinical competencies of physical therapy students. Physical Therapy 79:653-671

Simpson JM, Dyer J, Revell G 1993 Rehabilitation of elderly people: What should physiotherapy students learn on clinical placements? Physiotherapy 79:628-632

Simuzingili T, Amosun SL 1998 What clinical competencies do we expect from physiotherapy students at the University of the Western Cape? South African Journal of Physiotherapy, 54, 4, 10-14

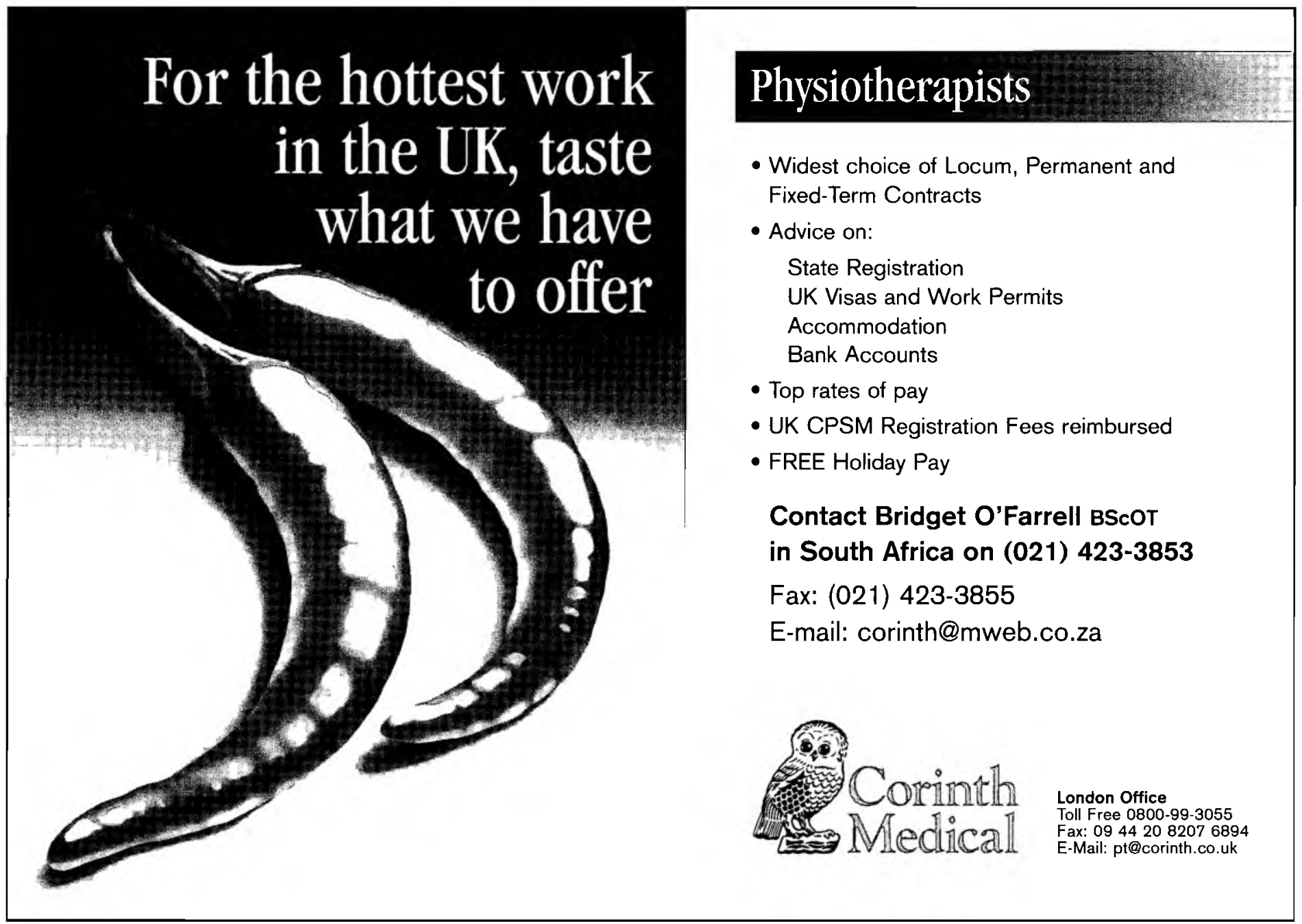

